\title{
LINKING SURFACE AND SUB-SURFACE VARIABILITY IN DRAKE PASSAGE
}

\author{
Graham Quartly', Jesus Gómez-Enri ${ }^{1}$ and Gabriel Navarro ${ }^{3}$
}

\author{
${ }^{1}$ National Oceanography Centre, Southampton, UK, ${ }^{2}$ University of Cadiz, Puerto Real (Cadiz), Spain, \\ ${ }^{3}$ Instituto de Ciencias Marinas de Andalucia, CSIC, Puerto Real (Cadiz), Spain
}

\begin{abstract}
The Antarctic Circumpolar Current (ACC) is the largest current in the world, with a mean transport of $134 \mathrm{~Sv}$, and it provides a significant barrier to the oceanic transfer of heat from mid-latitudes to polar regions. Infrequent full-depth hydrographic sections have shown large variability in the transport of the ACC and the position of its constituent fronts. The many sources of satellite remote-sensing data, with much more frequent sampling, offer another vista on such variability. The question we address here is how the spatial patterns and modes of variability recorded from satellite data relate to the observations from ships. In this paper, we confine our studies to height and temperature data from sensors that are unaffected by clouds, and thus provide near-complete records along the same. The seasonal variations in temperature are deeper south of $60^{\circ} \mathrm{S}$, whereas the interannual variations, associated with meandering fronts, occur further north and are deeper. The variability signal from altimetry lies further north again.
\end{abstract}

Index Terms - Polar Front, Sea surface temperature, Dynamic height, altimetry, XBTs

\section{BACKGROUND}

The Antarctic Circumpolar Current (ACC) is a deep persistent flow, linking the Atlantic, Indian and Pacific Oceans, and has 3 main fronts associated with it. These are the Subantarctic Front (SAF), the Polar Front (PF) and the Southern Antarctic Circumpolar Current Front (SACCF), each of which is characterised by a change in water properties (see [1] for example). Drake Passage (DP), the gap between South America and the Antarctic Peninsula, is the narrowest "choke point" of the ACC i.e. the ideal location for frequent sections guaranteed to cross the entire flow of the ACC. Although in deep water at the southern tip of South America, the SAF is found in shallower water a little further east (see Fig. 1), with it roughly following the $1000 \mathrm{~m}$ isobath around Burdwood Bank and along the continental shelf past the Falklands. Significant transport is associated with the SAF and PF (mean flows of $53 \mathrm{~Sv}$ and $57.5 \mathrm{~Sv}$ respectively [2]) and they limit the mixing of warm temperate waters with those from further south. Indeed, eddies (most of them being generated by meanders in the fronts) are the major mechanism for oceanic heat transport across strong mean flows. Eddies also contribute to transport biogeochemical properties from coastal areas into deep waters in the DP, where the coastal margins play an important role in the global carbon cycle..

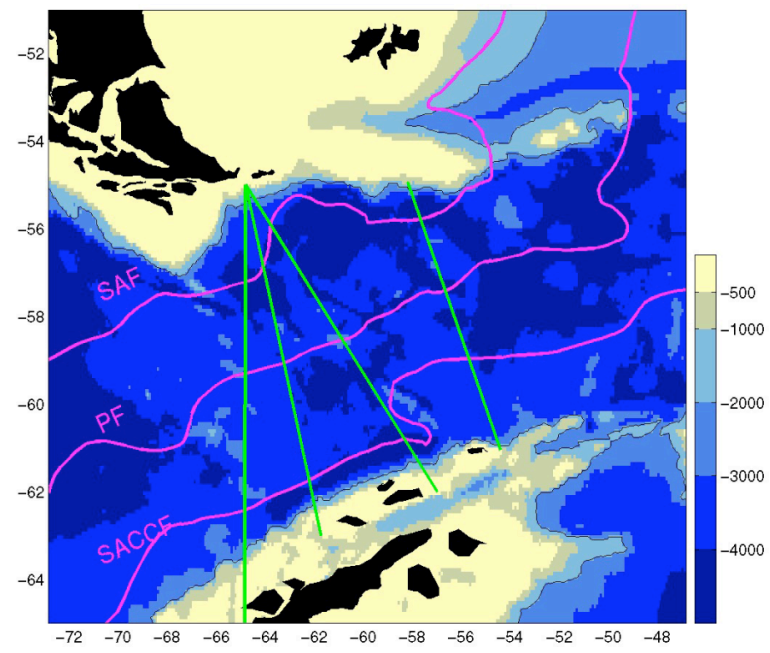

Fig. 1. Bathymetry of study region, with mean positions of fronts (from [3]) and locations of the 3 main routes for XBT sections, plus (at $55^{\circ} \mathrm{W}$ ) the WOCE repeat section SRIb occupied on a nearly annual basis with full-depth CTDs.

\subsection{Expendable bathythermographs (XBTs)}

We make use of XBT data collected along supply routes linking the southern tip of South America with the 3 US research bases on the Antarctic Peninsula (see Fig. 1). XBTs are probes dropped from the stern of a ship, and providing temperature profile data without the ship needing to stop. For these sections, XBTs reaching $900 \mathrm{~m}$ were normally used, with probes being launched typically every $15 \mathrm{~km}$ along track, but with finer spacing near the expected location of fronts. We make use of the quality-controlled data provided by Scripps Institute of Oceanography at regular depth intervals of $10 \mathrm{~m}$ (http://www-hrx.ucsd.edu). A common definition of the position of the PF is the southernmost position where the temperature at $200 \mathrm{~m}$ depth $\left(\mathrm{T}_{200}\right)$ is at least $2^{\circ} \mathrm{C}[1]$. However, the precise location of a 
front can be sensitive to the depth chosen or slightly biased readings from an individual XBT (see $\mathrm{T}_{200}$ line in Fig. 2). This figure also shows a cold eddy further north of the PF; a warm eddy to the south of the PF would also confuse a front definition based on southernmost location of a particular water mass. Such ambiguity may be resolved through frequent repeat XBT sections and/or the use of satellite data to give a broader spatial context. We downloaded all the XBT data available (1996 to 2004). Of the 56 sections, 28 closely matched the central line (Fig. 1), with at least 5 surveys in each 3-month meteorological season (Dec-Feb, Mar-May, Jun-Aug and Sept-Nov).

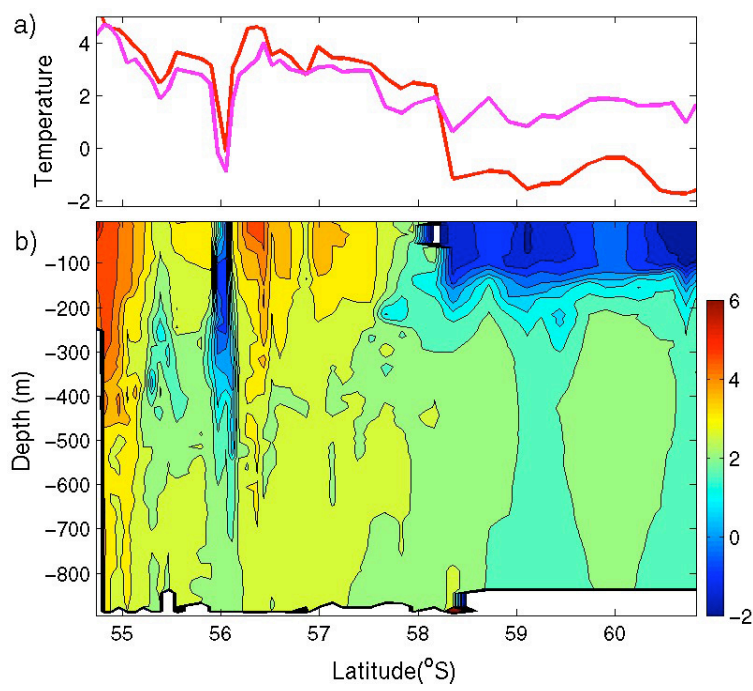

Fig. 2. XBT section (Sept. 1996) showing a) temperature at surface (red) and at $200 \mathrm{~m}$ (magenta), b) full-depth section. All temperatures are in ${ }^{\circ} \mathrm{C}$. Note the narrow eddy at $56^{\circ} \mathrm{S}$.

\subsection{Satellite data}

In this paper we make use of two sources of satellite data. The first is sea surface temperature (SST) data from the AMSR-E sensor on Aqua. This is a passive microwave sensor which allows it to measure the ocean surface through clouds, albeit that its spatial resolution $(\sim 50 \mathrm{~km})$ is poorer than that from infra-red sensors. We downloaded daily AMSR files processed by Remote Sensing Systems (http://www.remss.com) and made 7-day composites.

We also downloaded sea surface height ( $\mathrm{SSH}$ ) data (DUACS "Update" product) from CLS/AVISO (http://www.aviso.oceanobs.com). This product, available at 7-day intervals, makes use of all the altimeters operating at that time. Fields are available as i) absolute dynamic topography (ADT), with geostrophic flow expected to follow the contours (although ADT also contains significant error due to uncertainties in the geoid), and ii) SSH anomaly (SSHA), which shows the change in SSH associated with a departure from the nominal mean flow.

\section{VARIABILITY IN DATASETS}

First, we separately analyse the variability in each of the datasets, before combining them.

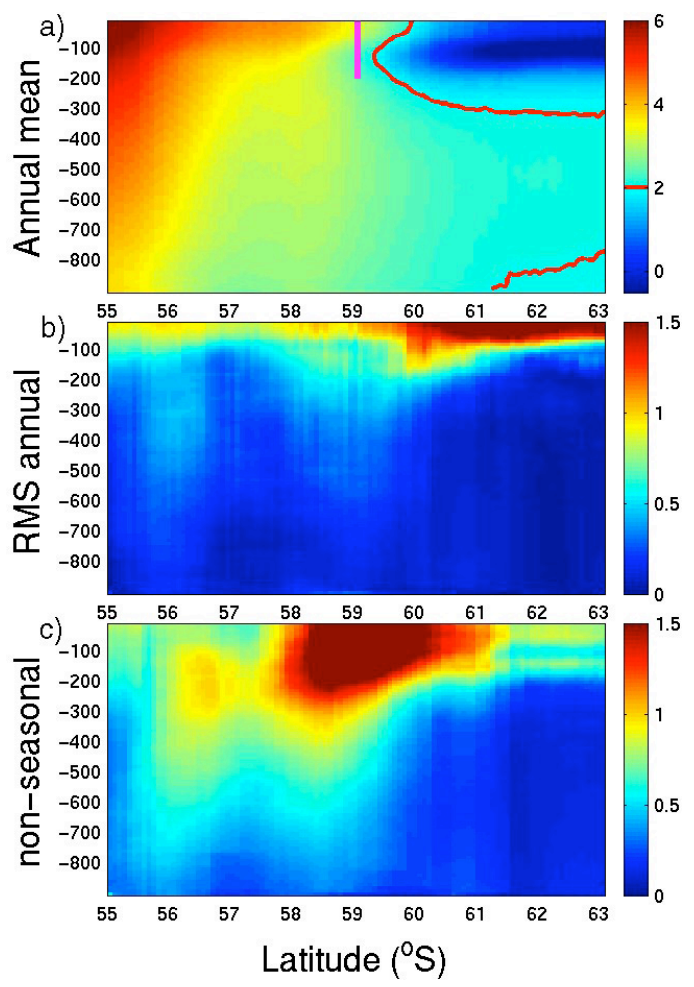

Fig. 3. Synthesis of XBT sections along central line. a) Mean temperature $\left({ }^{\circ} \mathrm{C}\right)$ (weighted equally for each season), b) R.m.s. difference $\left({ }^{\circ} \mathrm{C}\right)$ of seasons from annual mean. c) Average variability within a season (principally interannual variability). Pink line in top plot shows location of PF along this section according to [3], and red line highlights the $2{ }^{\circ} \mathrm{C}$ isotherm.

\subsection{Variability in XBT profiles}

The XBT data were interpolated in regular steps along the mean section, and mean and variability (standard deviation) calculated for each season. Figure 3 a shows the averages of the 4 seasonal means, showing that the coldest water (in the Antarctic Zone) only extend over the top $200 \mathrm{~m}$. This is the case for each season individually (not shown) as the coldest waters are fresh and therefore relatively buoyant. Significant spatial changes in temperature are seen throughout the top $900 \mathrm{~m}$ of the water column. The melt water generates a subsurface temperature minimum; consequently the $2^{\circ} \mathrm{C}$ isotherm lies on average $\sim 50 \mathrm{~km}$ further north at $200 \mathrm{~m}$ than it does at the surface. The indicated mean position of the PF from Orsi et al. [3] does correspond to a different period.

For the r.m.s.. difference of the seasonal averages from the annual mean (Fig. 3b) the main changes are in the top $100 \mathrm{~m}$, with the largest variation (up to $1.5^{\circ} \mathrm{C}$ ) south of the Polar Front. Some deeper signal $(200-500 \mathrm{~m})$ can be seen 
around $56^{\circ} \mathrm{S}$ and $59^{\circ} \mathrm{S}$, possibly due to aliasing of the interannual signal. Figure $3 \mathrm{c}$ shows the mean of the variability observed within each meteorological season; this principally represents interannual variations. It is striking that the greatest variability is now located at the Polar Front and is much deeper, with a secondary sub-surface peak at $56.6^{\circ} \mathrm{S}$ (just to the north of the nominal mean position of the $\mathrm{SAF}$, which is $56.8^{\circ} \mathrm{S}$ for this section [3]). This subplot thus highlights changes in temperature associated with meandering of the fronts and possibly eddies, rather than changes in solar heating (which would be concentrated at the surface).

\subsection{Variability in SST}

The 5 years of AMSR 7-day composites were analysed to give a mean (Fig. 4a) and variability (Fig. 4b). Between $70^{\circ}$ and $58^{\circ} \mathrm{W}$, the accepted mean PF coincides with the surface $2^{\circ} \mathrm{C}$ isotherm, but further east the $\mathrm{PF}$ is in significantly warmer water. Defining the front by sharpest spatial gradient, Dong et al. [4] produced a PF from 3 years of AMSR data. This definition, which matched a SST of $1{ }^{\circ} \mathrm{C}$ within DP but more than $4^{\circ} \mathrm{C}$ in the middle of the Atlantic sector, followed a very similar path to that of Orsi et al. [3]. An exact match should not be expected, because the datasets correspond to different periods, and one definition is based on sub-surface temperatures. The variability (Fig. 4b) is strongest along the PF, with some of the largest values west of the XBT section. A major part of the variability is due to the seasonal cycle; by fitting and subtracting a simple sinusoid from the SST at each individual location, we remove this annual signal. Now, the greatest variability occurs to the north of the PF, with much less west of the choke point.

\subsection{Variability in SSH}

The mean dynamic topography (MDT) for 1993-1995 shows a height change of $\sim 1.5 \mathrm{~m}$ across the entire ACC (Fig. 4d). The height contours at $0.50 \mathrm{~m}$ and $1.05 \mathrm{~m}$ are emphasised to show that within the confines of the channel they closely match the historical positions of the PF and SAF from independent ship-based measurements [3], but east of $56^{\circ} \mathrm{W}$ they diverge. Velocity anomalies are inferred from the spatial gradients of SSHA and the variance of these currents is expressed as eddy kinetic energy (EKE). Figure 4e shows that there is minimal EKE south of the PF or north of the SAF (the shallow conditions being unable to support the deep eddies generated by these flows). Indeed, the largest variability is at the eastern end of DP, where the fronts and flow are less constrained by bathymetry. Interestingly, the band of peak EKE lies $\sim 70 \mathrm{~km}$ north of the peak in SST variability (Fig. 4c).

As the gradient of SSHA only gives velocity anomalies, the actual flow pattern can be hard to disentangle. However, the Okubo-Weiss parameter may be used to define locations where rotational flow dominates over velocity shear [5], and this used to pinpoint centres of eddies. Figure $4 \mathrm{f}$ shows a census of eddy centres from each 7-day composite through the 15 years analysed. In this case, we use a detection threshold of $10^{-10} \mathrm{~s}^{-1}$ (which is larger than used by [5] but implies we are only counting the most prominent eddies). Typically we find 28 eddies in each weekly composite for the area shown; clearly many of these are long-lasting and occur in many successive scenes. This interpretation of the SSHA field also finds most of the activity to be between the $\mathrm{PF}$ and SAF, matching closely the distribution shown by the EKE (Fig. 4e). Segregating these eddies into cyclonic and anticyclonic (according to whether their SSHA signature is negative or positive), we find that when using our high detection threshold, there are $30 \%$ more cyclones than anticyclones. If we use a much lower threshold in keeping with [5], we detect many more eddies and then the numbers are evenly balanced between cyclones and anticyclones.

\section{SATELLITE-XBT MATCH-UPS}

The 28 XBT sections along the central line were analysed to look at the range of locations and conditions associated with the $\mathrm{PF}$, with the properties being considered of the station just south of the front (characteriesed by $\mathrm{T}_{200}<2^{\circ} \mathrm{C}$ ). As the front is quite pronounced in temperature, and the sampling interval of order $10 \mathrm{~km}, \mathrm{~T}_{200}$ just south of the $\mathrm{PF}$ was typically $1.5^{\circ} \mathrm{C}$ (see Tab. 1). Results are also presented for the 10 sections that were completely free of eddies. The uncertainty is, in most cases lower, although the number of samples is small for statistical analysis. The surface temperature (here $5 \mathrm{~m}$ depth) at the corresponding locations was warmer $\left(2.8^{\circ} \mathrm{C}\right)$ and had greater variability. The latitude of the front was $57.7^{\circ} \mathrm{S}$, with an r.m.s. variation of $1.0^{\circ}$ i.e. $110 \mathrm{~km}$; Orsi et al [3] locate the front at $58.9^{\circ} \mathrm{S}$, whilst 3 years of AMSR data showed it varying between $58^{\circ}$ and $59^{\circ} \mathrm{S}$, with a variability of $\sim 80 \mathrm{~km}$. (Fig. 6 of [4]).

\begin{tabular}{|lll|}
\hline & All cases & Eddy-free \\
\hline T200 $\left({ }^{\circ} \mathrm{C}\right)$ & $1.5 \pm 0.5$ & $1.4 \pm 0.5$ \\
Surface temp. $\left({ }^{\circ} \mathrm{C}\right)$ & $2.8 \pm 1.3$ & $2.4 \pm 1.2$ \\
Latitude $\left({ }^{\circ} \mathrm{S}\right)$ & $57.7 \pm 1.0$ & $58.1 \pm 0.7$ \\
ADT $(\mathrm{m})$ & $0.74 \pm 0.14$ & $0.68 \pm 0.10$ \\
\hline
\end{tabular}

Table 1. Geophysical parameters at location of Polar Front along central XBT section. Central column is for all 28 cases; righthand values are for those 10 guaranteed eddy-free.

We considered the matching altimetry fields and found that the PF location for XBTs corresponded to ADT $=0.74 \mathrm{~m}$ $( \pm 0.11 \mathrm{~m})$. However, in using an altimetry product that has been smoothed and interpolated to a regular $0.25^{\circ} \times 0.25^{\circ}$ grid, we lose some of the altimeter's fine scale $\left(\sim 0.05^{\circ}\right.$ along-track) sampling. 


\section{SUMMARY AND FUTURE WORK}

There has long been known to be great variability associated with the ACC, both in terms of the position of its constituent fronts and the transport associated with them [2]. Repeat XBT sections along an Antarctic supply route show that the seasonal variations in temperature are mostly confined to the top $100 \mathrm{~m}$ and to the south of the Polar Front (Fig. 3b). Non-seasonal variations, combining both inteannual and intra-seasonal, are located close to the mean positions of the $\mathrm{PF}$ and SAF and penetrate much deeper (Fig. 3c). Satellite data afford a more frequent and complete view, albeit only for the surface. AMSR data show that non-seasonal changes in SST occur mainly to the north of the PF (Fig. 4c) whilst altimeter data show both current variability (Fig. 4e) and eddy centres (Fig. 4f) to be $\sim 70 \mathrm{~km}$ further north again.

For the central XBT section, we have related the subsurface definition of the PF to surface parameters that can be measured by satellite. We plan to extend this to the other (less frequently occupied) XBT lines and the WOCE repeat line SR1b further east (see Fig. 1). The frequent complete SST coverage by AMSR will allow us to look specifically at the intra-seasonal variability. We have also noted that eddies in DP affect the growth of phytoplankton, and can thus be followed and monitored through changes in satellitederived chlorophyll concentration [6]. We hope to be able to quantify the enhancement in productivity due to eddies in this region.

\section{ACKNOWLEDGEMENTS}

This work has been done under the auspices of the International Polar Year (IPY), activity ID $\mathrm{N}^{\mathrm{o}}$ : 132 (expression of interest ID No 567 -IRACETSO)

\section{REFERENCES}

[1] Pollard, R.T., M.I. Lucas, and J.F. Read, "Physical controls on biogeochemical zonation in the Southern Ocean,", Deep Sea Res. II 49, 3289-3305, 2002.

[2] Cunningham, S.A., S.G. Alderson, B.A. King, and M. A. Brandon, "Transport and variability of the Antarctic Circumpolar Current in Drake Passage," J. Geophys. Res., 108, art. 8084, 2003.

[3] Orsi, A.H., T. Whitworth III, and W.D.J. Nowlin, "On the meridional extent and fronts of the Antarctic Circumpolar Current," Deep-Sea Res. I, 42, 641-673, 1995.

[4] Dong S.F., J. Sprintall, and S.T. Gille," Location of the Antarctic Polar Front from AMSR-E satellite sea surface temperature measurements", J. Phys. Ocean., 36, 2075-2089, 2006.

[5] Isern-Fontanet, J., Garcia-Ladona, E., Font, J., "Identification of marine eddies from altimetric maps," J. Atmos. Ocean. Technol., 20, 772-778, 2003.

[6] Gómez-Enri, J., G. Navarro, G.D. Quartly, and P. Villares, " Characterizing and following eddies in Drake Passage", Proc. IGARSS 2007, Barcelona (4pp.)
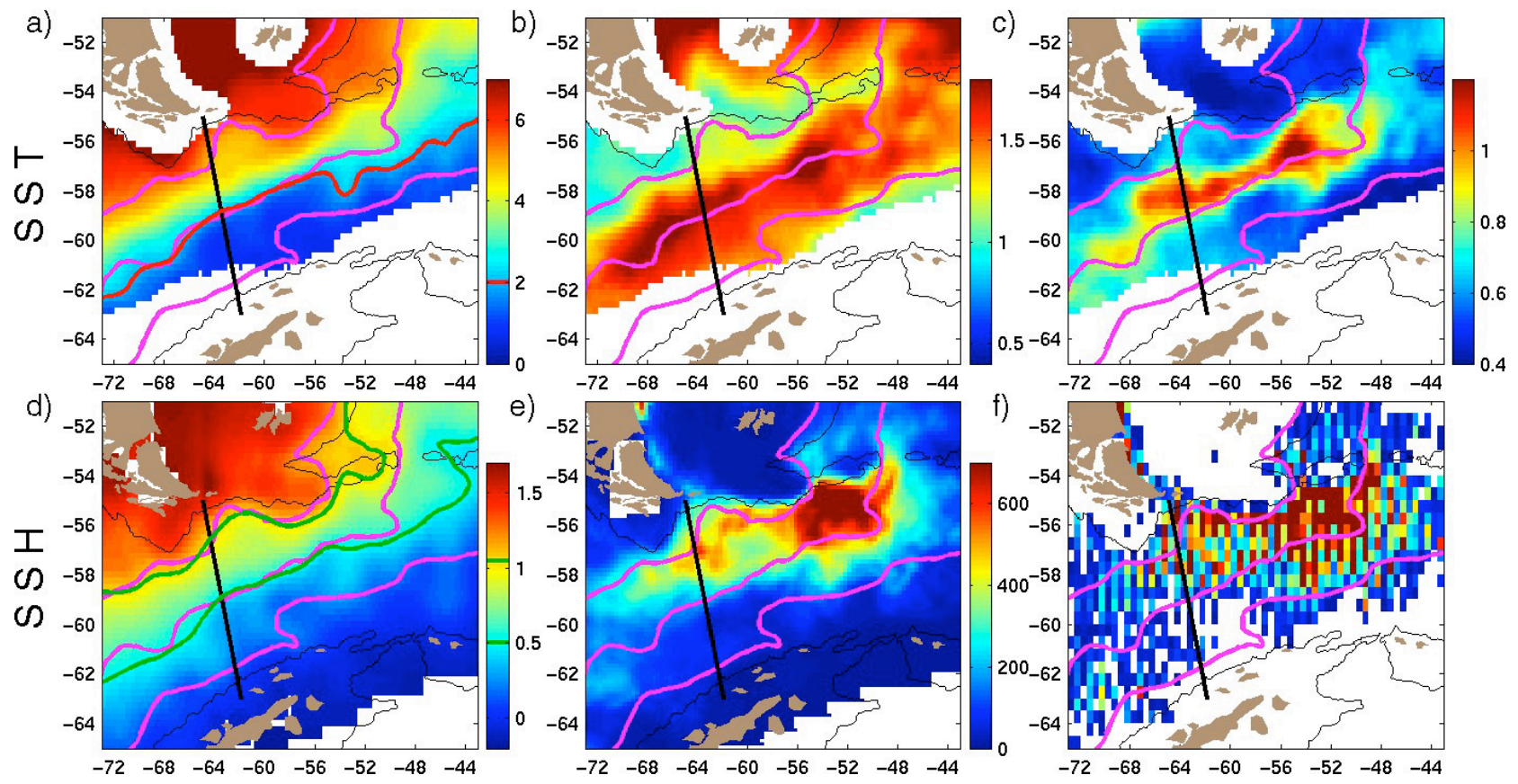

Fig. 4. Synthesis of multi-year satellite data. a) Mean SST $\left({ }^{\circ} \mathrm{C}\right)$, b) Std. dev. of SST $\left({ }^{\circ} \mathrm{C}\right)$, c) Std. dev. of SST once annual cycle removed $\left({ }^{\circ} \mathrm{C}\right)$, d) Mean dynamic topography $(\mathrm{m})$, e) Eddy kinetic energy $\left(\mathrm{cm}^{2} \mathrm{~s}^{-2}\right)$, f) Population density of eddies. Added lines in all plots indicate $2000 m$ isobaths (thin black), central XBT section (thick black) and mean position of fronts from [3] (magenta). The extra red line in a) highlights the $2{ }^{\circ} \mathrm{C}$ contour; the green lines in d) the $0.50 \mathrm{~m}$ and $1.05 \mathrm{~m}$ contours. 